\title{
The Elusive Agenda: Mainstreaming Women in Development
}

\author{
ROUNAQ JAHAN
}

\section{THE ELUSIVE AGENDA}

A report in 1975 by the International Labour Organisation(ILO) caught world attention by pointing out that while 'women and girls constitute one-half of the world's population and one third of the official labour force' and 'perform nearly two-thirds of work hours', they 'receive only one-tenth of the world's income and less than one-hundredth of the world's property."

Nearly twenty years later, a report by the United Nations-UNDP's Human Development Report 1994-found that, despite advances in labour-force participation, education and health, women still constitute about two-thirds of the world's illiterates, hold fewer than half of the jobs on the market and are paid half as much as men for work of equal value. Women make up only about 10 percent of the world's parliamentarians and less than 4 percent of cabinet members. The report concludes that 'in no society are women secure or treated equally'.

The unmistakable achievements in areas like education and health show that progress is possible, but the continued disparities in others such as income and decision-making indicate that there is still a long way to go. However, the statistical evidence about continued disparities should not detract us from recognising the major achievements of the last two decades. There has been a sea-change in knowledge and awareness. Affirmative action policies have been introduced. Special measures have been designed to remove barriers to women's participation. Women's voices are stronger than ever. And women are increasingly learning to take control of their own lives and bring their perspective to bear on decisions affecting their communities, nations, and the planet. These changes in awareness, expertise, policies, laws and women's voice were brought about by the efforts of many different actors-women's movements as well as national governments and international donor organisations.

Rounaq Jahan teaches in the South Asia Department of Colombia University, New York.

Author's Note: This article is based on my earlier publication, The Elusive Agenda: Mainstreaming Women in Development . London: Zed Books, 1995.

${ }^{1}$ ILO, Women at Work, Geneva, January 1975, quoted in United Nations, The State of the World's Women, 1979.

${ }^{2}$ UNDP, Human Development Report 1994, p. 31. 
The achievements of the past decades have been hard won. Twenty years ago, when the women's movement raised the issue of gender equality, national governments and international donor agencies accepted the goal in principle, but they did not have any ready-made policy or instrument to address the set of concerns brought forward by women. Developing policies, designing tools and implementing them took time. The goal of women's movement was nothing short of changing the very direction of development. Removing gender disparities in human development and access to opportunities implied changing priorities and redistributing resources; the elimination of discriminatory practices meant changing laws and customs that have prevailed over centuries. There was resistance to change, created by ignorance, bias and conflicts of interest. The women's agenda was not clearly understood or appreciated, and it was also threatening as it implied fundamental restructuring of society and institutions. Even when awareness was raised and women in development (WID)/gender and development (GAD) policies and measures were adopted by states and international donor agencies, implementation was difficult.

By now, there is a growing realisation that, though a good start has been made, many of the objectives laid down by the donors and their development partners have still not been achieved. Gaps have emerged between intentions and results. Policy objectives were not clear and needed specificity. There have been few measurable goals against which progress can be measured. Policy and programme interventions have not been adequate to ensure results. Institutional frameworks have been week and required strengthening.

The experiences of the last two decades indicate that while we need to acknowledge significant gains in several fronts, we also need to acknowledge that the fundamental objectives of the women's movement, particularly that of the South e.g. transforming social and gender relations and creating a just and equal world, still elude us. And indeed, poverty among women has increased even in the richest countries; women's labour-force participation has grown, but the terms and conditions of their employment have not improved. The central issue that need to be addressed is: why has progress been so elusive for women? What explains the contradictory trends-heightened advocacy and awareness of gender issues on the one hand, and the growing poverty of the world's women on the other? Is progress elusive because the women's agenda has not been clearly defined, or is it because policies and measures have not adequately addressed that agenda? How should progress be measured: by efforts or by results? Are policies and strategies essentially on the right track, needing only more time and better implementation, or do they need reorientation?

There are, of course, no simple answers to the above questions. The women's movement did articulate an agenda-equality, empowerment, and the transformation of existing development paradigms emerged as core concerns. But this challenged 
mainstream thinking and the global power structure so dramatically that the initial response of international and national bureaucracies was to ignore a large part of the women's agenda, on the ground that these social issues did not 'fit' into organisation's and government's operations. Their stand was countered by the advocates of gender equality in two ways. At one level, efforts were made to demonstrate why international donor agencies and national governments should be concerned about gender issues and how they can be 'fitted' into agency and governments' processes, procedures and operations. ${ }^{3}$ The efficiency and anti-poverty arguments were developed to justify investment in women, arguing that such investment would lead to economic growth as well as poverty alleviation. ${ }^{4}$ At another level, the women's movement pressed for changing the existing assumptions, theories and models of development. It underscored the importance of social policies and the need for a people-centred development model. The movement urged changing organisational rules and cultures to move towards inclusive and participatory processes, women's voices in decision-making, greater transparency and account-ability, and so on.

Donor Agencies and state policies responded more favourably to the first level of argument, which did not demand structural changes. But in areas where investment in women required the redistribution of power and resources-sharing responsibilities in reproductive labour, gender equality in land and property rights, a voice in decision-making, and so on-donor agencies and states were less responsive. The idea of investment in women could be sold to the agencies and governments when it was possible to demonstrate that there would be quick economic returns (e.g. income and employment projects, micro-enterprises, export-led growth strategies), or if it was linked to reaching other development goals (e.g. controlling population growth), but the proposition was less successful if it was made on the grounds of women's rights, or the promotion of women's empowerment.

The crux of the issue was power and resources. For many within agencies and governments, empowering women meant giving up male power and privilege. ${ }^{5}$ Investment in women implied either reallocating existing resources or finding additional sources of revenue. In the absence of women's demonstrated political power as a constituency, the national and international bureaucracies were under no pressure to choose either option.

But building women as a political constituency was difficult. Women are not

${ }^{3}$ Johanna Schalkwyk, 'Looking Forward: Some Considerations for WID Strategies', unpublished paper, 1994.

${ }^{4}$ Caroline O. N. Moser, Gender Planning and Development: Theory, Practice and Training. London and New York: Routledge, 1993.

${ }^{5}$ Kathleen Staudt, Women, Foreign Assistance and Advocacy Administration. New York: Praeger, 1985. 
a homogeneous category, but are differentiated by class, race and nation, and often their choices and opportunities are determined more by these factors than by their gender. While on issues like rights and security women could be united in their stand, other issues such as poverty and entitlement were much more divisive. The movement's failure to take a consistent stand on a core agenda allowed donor agencies and states to come forward with a partial response. Generally they took measures that did not involve any hard choices-creating under funded mandates, adding a few projects to their existing portfolios, and supporting research, training and the development of operational tools and techniques. But they shied away from legal and institutional reforms to remove barriers to women's equal participation, and continued to promote macro-policies that exacerbated inequalities between classes and nations. This uneven response by agencies and states explain the mixed resultsthe heightened advocacy and awareness of gender issues on the one hand, and increased poverty among women on the other. The agencies and governments argued that it was lack of understanding and expertise preventing them from achieving their WID/GAD policy objectives. But they underplayed the political economy of the process of change: how the disparities in power and resources and conflict of interest might obstruct achievement of WID/GAD policy objectives.

The international agencies pursued by the WID/GAD policies and measures emphasised instrumental objectives, such as integration and mainstreaming, rather than substantive objectives like gender equality and women's empowerment. They gave priority to institutional strategies, in the hope that once institutionalised gender concerns would become legitimate, and they would get routine attention in agency operations and access to regular budget provisions. Some of the efforts bore fruit: WID/gender issues became legitimate concerns in agency discourse and operations. But this emphasis on institutionalisation also resulted in WID/GAD often losing sight of the women's agenda. Agencies monitored adoption of WID/GAD policies and measures, rather than the impact of these measures on the ground in achieving the substantive objectives of gender equality and women's empowerment.

What lessons can be drawn from the experiences of the last two decades? Where do we go from here? One lesson that can be drawn is that in future, policies and measures should more clearly address the women's agenda. Instead of trying to fit gender issues into every sector, the focus should move towards an agenda-setting approach.

\section{FROM AN INTEGRATIONIST TO AN AGENDA-SETTING APPROACH}

What will shift towards an agenda-setting approach involve? It will necessitate changes on many fronts-in decision-making structures and processes, in articulation

of objectives, in prioritisation of strategies, in the positioning of gender issues amidst 
competing emerging concerns, and in building a mass base of support among both men and women.

Agenda-setting, first of all, implies leadership. Women will have to play a proactive role. This will require a change in existing decision-making structures and processes, which will need to be more inclusive. Women who are affected by development interventions, or their organisations, need to participate in decisionmaking structures, which will need to be made democratic and participatory. Only through a voice in decision-making can women aspire to shape the objectives, priorities and strategies of development, and start to transform the development agenda. An agenda-setting approach will naturally imply a focus on agendas, which involve a clear articulation of a women's core agenda. Since women are not a homogeneous category, such an agenda will have to represent the interest of different classes and groups of women. Policies and interventions would have to address the issues on such a women's agenda. Since the poor and the underprivileged constitute the majority of the world's women, interventions benefiting them will need to be prioritised over measures benefiting more affluent and privileged women.

Within the international agencies, an agenda-setting approach will involve greater attention to the substantive objectives of the women's movement: gender equality and women's empowerment. The agencies' preoccupation with instrumental objectives-such as integration and mainstreaming, and WID/GAD institutionalisation-will have to give way to prioritising operational issues-removing legal and institutional barriers to women's equal participation and designing and implementing gender-responsive policies and interventions.

An agenda-setting approach will require strategic positioning of gender concerns in a period of change. Within donor agencies, this will involve linking with and influencing other emerging mandates. Outside the agency, it will require the women's movement to seize the political space being opened up by the emergence of new democracies and the growing strength of civil society. Women are already participating in increasing numbers in citizens' groups and people's movement. This process needs to be strengthened to make women's voices heard, and to mobilise people's support behind the women's agenda. Women's participation in the political process is all the more critical as global economic restructuring threatens to undermine a significant part of the women's agenda, with the emphasis on rolling back the state and free trade and open markets signalling a trend towards a decrease in social safety nets and an increase in exploitation of women's cheap labour in productive activities and their unpaid labour in reproduction.

An agenda-setting approach would require giving primacy to women's agency-strengthening women's groups and organisations. These are still weak in many countries, with a narrow base dependent primarily on women's support. In many countries of the South, women's organisations and networks are heavily 
dependent on external donor funding. Their networking with the international women's movement, and with donor organisations, is often stronger than their networking with other organisations in their own countries. In future women's groups and movements need to enhance their base of popular support, devising strategies to strengthen their financial position and gain male support. In Southern countries, women's organisations need to identify domestic sources of funding.

A new communication strategy is needed to facilitate the expansion of support for the women's movement. Up to now, advocacy of gender issues has been perceived as a 'win/lose' scenario: women's gains have been seen as men's losses. In future, the message should be communicated as a 'win/win' scenario: changing gender roles and relations is good not simply for women-it also benefits men, families and communities, and would create significant inter-generational benefits. Additionally, the communication strategy should target the younger generation much more consciously. Here, advocates of gender equality can learn a lesson from the environmentalists. While the message of environmentalism has caught the imagination of both boys and girls, the message of the women's movement has had much less success with the boys. Indeed, the message of civil rights and equality, in general, has had much less success, despite its affirmation by the constitutions and the legal systems of different nations.

Agenda-setting would also involve the development of concepts and analytical tools in different languages and different development contexts. Concepts and methodologies are powerful tool to control agendas, as they can both include and exclude particular groups. Though many of the conceptual and methodologies innovations in WID/GAD have emerged out of grassroots innovations in the South, they have been systematised and packaged primarily in Western academic institutions or in the donor agencies, and in the English language. In future, greater attention needs to be paid to the development of concepts, analytical tools and models in the South. While developing new concepts and models, the women's movement has to be more vigilant in the future against the co-optation of language. Terms such as 'empowerment' are increasingly being used by the conservatives, but their agenda under 'empowerment' is very different from that of the women's movement. The movement has to assess carefully whether, in the name of 'empowerment' and 'responsibility', new policies and interventions are being promoted by the conservatives that will withdraw support and investment and at the same time increase women's burden.

Finally, an agenda-setting approach, in the context of international development assistance, would require building the institutional capacities of aid recipients to set and implement their own agendas. Though the professed objective of donor agencies is to assist the aid recipients in their own efforts to develop themselves, in reality it is in only a very few aid-recipient countries that the agencies have pursued a 
systematic and sustained effort to build national institutional capacity on gender issues.

\section{SHARED RESPONSIBILITY}

Though the development discourse of international agencies has paid routine homage to the notion of global interlinkages and sharing, in reality what has been happening in the global village is not sharing but cost-shifting. In the name of free competition and efficiency, people with power and privilege have been able to shift their costs onto the less privileged, and thus accumulate more. In the last half-century inequalities and disparities have grown rather than lessened. Agenda-setting would involve raising awareness about the need to share responsibilities more equitable in the future - a fair sharing between young and old, women and men, poor and rich, and South and North.

Shared responsibility should be the cornerstone of the new institutions we are trying to create to meet the challenges of the twenty-first century-the new family, community, state and global network. The old family structures are breaking down, primarily because of a male abandonment of responsibility and women's expanded responsibility to earn cash income. The family as an institution cannot be reinvigorated on the basis of the old notion of complementarity of role: it has to be based on shared roles and responsibilities. An emphasis on "family values" would imply a reminder to the father — whether married or not—about their responsibilities, and the need to shoulder their fair share of burden.

Communities would have to be rebuilt, again on the principle of shared responsibilities between rich and poor, men and women, public and private sector, and state and community-based organisations. Shared responsibility would imply not simply sharing work and burdens but also a voice in decision-making and equitable sharing of resources and revenue. Communities cannot be rebuilt on the notion of abandoning the rural areas and city slums, but only through a fair cost-sharing between rural and urban areas, suburbs and cities, and between rich and poor neighbourhoods.

In recent years, the state and its institutions have also faced increasing scrutiny. Government bureaucracies are criticised for not being efficient, responsive, transparent and accountable; talk of reforming the state and reinventing government is in the air. Again, future reforms of state institutions would have to be grounded in the principle of fair sharing: governments should deliver services to people in proportion to the revenue received from the people; they should be transparent and accountable; and they should share information with citizens and give citizens' groups a voice in influencing decisions. State institutions cannot be energised on the old notion of the state taking on total responsibility on behalf of the people: they 
would have to be strengthened on the basis of a greater sharing of responsibilities between the government and the non-governmental sector.

Finally, the global institutions and community would have to be restructured on the principle of burden-sharing. This would imply, first of all, a recognition of the unequal burdens on North and South; the net transfer of resources from the South to North through unequal terms of trade. The global institutions and community cannot be restructured on the basis of continued built-in disparities in transactions, but must be created on the principle of justice and fairness. For the women's movement the choice is clear. If the movement truly wants to transform the development agenda, it has to take a consistent stand in favour of fair burden-sharing at all levels-within the family, the community, the nation, and the world. 


\section{Comments}

Dr Jahan's presentation is far more comprehensive than the paper that has been circulated, and which I had read to comment on. In assessing the performance of two bilateral and two multilateral donor agencies in mainstreaming Women in Development with respect to their objectives; strategies; and the results achieved, Dr Jahan mentions the shifts in approaches; the corresponding adjustments that were made at the institutional level; and the means adopted by the agencies to measure progress. The tabular comparisons she has now shown us; and the references she makes to the cases of Bangladesh and Tanzania, make some of the linkages I thought might have been important to include, and treat in some detail. I will therefore devote my comments to the aspects on which a person with Dr Jahan's advantage, I feel, could further enlighten us.

The subject of the paper of course is important. Regional and global strategies have a bearing on the manner in which common social problems are dealt with at the national and local levels. An appropriate handling of these problems at the macro level can lend support to, and enable the 'particularity' of the problems of different contexts to be addressed more meaningfully.

The fact that Dr Jahan is an academic, and has also lent advise on the subject she is treating, to an United Nations organisation, places her at an advantage. She can not only present the insider's perspective; but as an academic, can refer to a much larger, and more rigorous framework of analysis that takes account of critical theory; the history of the development experience; and the impact of national and international events and movements that bear on outcomes. The assessment as such could cut across the limitations of similar evaluations that are made by the personnel of the agencies themselves; or by feminist groups whose struggles tend to be focused primarily on the problems of particular contexts. It is in this perspective that I feel more analytical detail could be included in the paper.

The discussion revolves around the internal structure and functioning of the donor agencies selected for analysis. The main referrants of performance are economic considerations; and the efforts to employ an equal number of men and women as personnel. Such a treatment tends to attribute prime importance to the existence and policies of these agencies themselves, rather than emphasising their raison d'etre. It is of course the women's agenda and the role the agencies seek to play in promoting that agenda which is the issue at stake. In other words, as Dr Jahan has observed in her presentation, 'equality' and 'empowerment' are separate issues. It is 'progress' in the promotion of the agenda that seeks to empower women, and the results of those efforts hence, that ought to be a measure of assessing performance.

Academic research and analyses have contributed significantly to the development initiative since the first steps were taken in that direction at the end of World War II, and the launching of Operation Camelot. An analysis of the performance of the donor agencies with reference to the history of 'development' 
therefore may have been in order; as may have been the feedback these agencies, and the development paradigm itself have received from the academy. The numerous failures of the experience, and the movements that have emerged from within societies (such as the women's movement in various countries), have in turn drawn attention to the dynamics of the tensions of the current world context; and the lessons to be learnt from previous failures for the purposes of planning at different levels. The insights provided by the academy have been instrumental in pressing for a definition and a redefinition of the different approaches that have been adopted.

It may also have been useful to discuss the interaction between, and the influences of the policies of the agencies upon each other. If representatives of bilateral agencies sit on the Board of the multilateral agencies, what effect, if any, does that presence have on the policies of both, and what is the impact of those policies at the national and local levels. The bilateral agencies that have special policies to promote women's advancement, moreover, such as CIDA, NORVIB, and NORAD, etc., collaborate with each other, and they co-finance components of projects in keeping with their priorities and financial constraints. This collaboration does not necessarily have a positive effect on the outcome of the project in so far compliance with the demands of various agencies on the implementing organisations is concerned. Similarly, the author could have examined how the development strategies followed by the World Bank and the UNDP impact on the policies of bilateral agencies, given the influence (as the author observes) that the latter agencies "wield in shaping the development strategies of the countries of the South" (p. 2). The influence that the multidonor agencies have on the governments of the countries of the South could have furthermore been related to declared state priorities on the one hand; and the consequences of the policies actually followed, or possible, at the grass roots level, on the other.

The author judges the performance of bilateral agencies to be more in keeping with their stated objectives than the performance of multilateral agencies. The reasons for the difference are not discussed in any detail; nor are any recommendations made that could serve to 'improve' performance. Given the fact that institutions are made by peoples themselves, the lessons learnt from past experience can therefore enable the structure of those institutions to be revised in order to identify, and meet the requisites of defined objectives.

We would all agree that there is more to the women's movement, and the institutional responsibilities to address women's problems, than simply to add more women to existing institutional frameworks. We, however, would have liked to know Dr Jahan's recommendations on how this could be facilitated within the donor/state/ NGO nexus of the current development paradigm.

Pakistan Institute of Development Economics,

Soofia Mumtaz Islamabad. 